\title{
INFECÇÃO DE SEMENTES E ANORMALIDADE DE PLÂNTULAS DE FEIJÃO, EM FUNÇÃO DO CONDICIONAMENTO OSMÓTICO INDUZIDO POR POLIETILENO GLICOL-6000
}

\author{
Messias Firmino de Queiroz ${ }^{2}$, Pedro Dantas Fernandes ${ }^{3}$ \& Francisco de Assis Cardoso Almeida $^{3}$
}

\section{RESUMO}

Sementes de dez cultivares de feijão (Phaseolus vulgaris L.) foram submetidas a seis níveis de tensão osmótica $(0,-0,2,-0,4,-0,6,-0,8$ e - 1,0 MPa) induzidos por polietileno glicol-6000 (PEG-6000) com o objetivo de se estudar os seus efeitos sobre a percentagem de sementes infectadas e plântulas anormais, durante teste de germinação, identificando-se os genótipos mais tolerantes. O experimento foi conduzido em germinador com temperatura e umidade relativa controladas, utilizando-se como substrato o papel-toalha com $\mathrm{pH}$ neutro. O delineamento experimental foi inteiramente casualizado, em esquema fatorial $10 \times 6$, com 4 repetições contendo, cada uma, cinqüenta sementes, para o teste de germinação. Segundo os resultados obtidos, a percentagem de sementes infectadas aumenta à medida que se elevam os níveis de concentração do PEG-6000. Na maior parte dos genótipos aumenta a anormalidade com a concentração de PEG-6000 até a faixa de pressão osmótica entre - 0,6MPa e - 0,8MPa, com exceção das cultivares 'Goytacazes' e 'Onix', em que foi sempre crescente com a concentração de PEG-6000. A cultivar 'Corrente' teve sempre os menores índices de anormalidade e de infecção, podendo ser classificada como a mais tolerante. As cultivares 'Novo Jalo', 'Jalo Precoce' e 'Goytacazes' foram as mais afetadas por infecção de sementes e anormalidade de plântulas.

Palavras-chave: PEG-6000, tensão osmótica, germinação, genótipo, tolerância

\section{SEED INFECTION AND SEEDLING ABNORMALITIES OF BEAN UNDER OSMOTIC CONDITIONING INDUCED BY POLYETHYLENE GLYCOL-6000}

\begin{abstract}
Seeds of ten bean cultivars (Phaseolus vulgaris $\mathrm{L}$.) were submitted to six levels of osmotic tension $(0,-0.2,-0.4,-0.6,-0.8 \mathrm{e}-1 \mathrm{MPa})$ induced by polyethylene glycol-6000 (PEG-6000), with the purpose of studying its effect on the percentage of infected seeds and abnormal seedlings during the germination test, identifying the most tolerant cultivars. The experiment was carried out in a germinator with temperature and relative humidity control, making use of a neutral $\mathrm{pH}$ paper towel as a substract. The experimental design was completely randomized in a $10 \times 6$ factorial scheme with four replications, each one consisting of 50 seeds for the germination test. The results obtained have shown that the percentage of infected seeds increases with the PEG-6000 levels. In most cultivars, the abnormality increases with the PEG6000 levels, until the concentrations of - 0,6 and $-0,8 \mathrm{MPa}$, with exceptions of cultivars 'Goytacazes' and 'Onix' in which the abnormality was always higher, increasing with the PEG levels. The cultivar 'Corrente' was the most tolerant to seed infection and to seedling abnormality. The most sensitive genotypes to seed infections and seedling abnormality were 'Novo Jalo', 'Jalo Precoce' and 'Goytacazes'.
\end{abstract}

Key words: PEG-6000, osmotic tension, germination, genotypes, tolerance

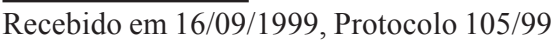

${ }^{1}$ Parte da Dissertação de Mestrado do primeiro autor

${ }^{2}$ Engenheiro Agrônomo, Professor Visitante da UEPb, CEP 58117 - 000, Lagoa Seca, PB. Fone: (0xx83) 321 8817, Fax: (0xx83) 366 1244. E-mail: mfq@terra.com.br

${ }^{3}$ Professor Doutor, Departamento Engenharia Agrícola/CCT/UFPB. Av. Aprígio Veloso 882, CP 10087, CEP 58109 - 970 , Campina Grande, PB. Fone: (0xx83) 310 1285, Fax: (0xx83)3101307.E-mail: pdantas@deag.ufpb.br, diassis@deag.ufpb.br 


\section{INTRODUÇÃO}

O feijão comum (Phaseolus vulgaris L.) é a espécie mais cultivada dentre as outras do gênero Phaseolus (P. coccineus, $P$. acutifolius e P. hinatus) representando cerca de $95 \%$ da produção mundial, sendo cultivada principalmente em climas tropical e subtropical; é a leguminosa mais importante para o consumo humano, por sua riqueza em proteína (20 a $25 \%$ ) constituindo-se na principal fonte de alimento de populações das Américas do Sul e Central, do Caribe e da África (Fiegenbaum et al., 1991).

Para o Brasil, além de seu caráter econômico, o feijão é um produto de alto significado social, plantado em 5,5 milhões de hectares, com produção anual em torno de 3,3 milhões de toneladas. A produtividade média nacional é considerada baixa, ao redor de $609 \mathrm{~kg} \mathrm{ha}^{-1}$ (Fageria, 1998).

A cultura do feijoeiro é exigente em água, durante a fase de germinação, com prejuízos ao stand e conseqüências sobre o rendimento final; devido à sua baixa rentabilidade econômica, os agricultores limitam investimentos em novas tecnologias, dentre as quais a irrigação, acarretando baixas produções por área (Rosolem, 1987). Por outro lado, no Nordeste brasileiro o cultivo se dá principalmente em condições de sequeiro. As constantes secas, irregularidade das chuvas e altas temperaturas, prejudicam a cultura, por limitar o conteúdo de água no solo, comprometendo o sucesso da germinação das sementes e o pleno estabelecimento das plantas (Sharma, 1976). Por isso, são importantes os estudos que visem à identificação de genótipos mais tolerantes ao estresse hídrico.

O polietileno glicol-6000 (PEG-6000) tem sido indicado por Bradford (1986) para estudos de estresse hídrico, em razão de simular, satisfatoriamente, os efeitos da estiagem sobre a germinação de sementes e o crescimento de plântulas; enquanto alguns autores se reportam ao fato de o PEG-6000 ser um produto inerte, sem qualquer toxicidade para as plântulas (Bradford, 1986; Villela, 1991), Nicnow et al. (1991) citam que o condicionamento osmótico de sementes em concentrações altas desse produto, pode prejudicá-las fisiologicamente, induzindo anormalidade e infecção.

Este trabalho foi desenvolvido com o objetivo de se estudar os efeitos do polietileno glicol-6000 sobre a incidência de plântulas anormais e sementes infectadas, durante a germinação de 10 genótipos de feijoeiro, identificando-se os mais tolerantes e os mais afetados.

\section{MATERIAL E MÉTODOS}

O trabalho foi conduzido no Laboratório de Sementes da Embrapa Algodão - CNPA, em Campina Grande, PB, no período de abril a junho de 1995, sendo estudados dez cultivares de feijão (Phaseolus vulgaris L.) e seis níveis de pressão osmótica, através da utilização de polietileno-glicol-6000.

As sementes das dez cultivares de feijão foram doadas pela Embrapa Arroz e Feijão (CNPAF/EMBRAPA) com sede em Santo Antônio de Goiás, GO. As cultivares estudadas foram: $C_{1}$-'A 285'; $C_{2}$ - 'Safira'; $C_{3}$ - 'Diamante Negro'; $C_{4}$ - 'São José'; $\mathrm{C}_{5}$ - 'Corrente'; $\mathrm{C}_{6}$ - 'Goytacazes'; $\mathrm{C}_{7}$ - 'Novo Jalo'; $\mathrm{C}_{8}$ - 'Jalo Precoce'; $\mathrm{C}_{9}$ - 'Xamego' e $\mathrm{C}_{10}$ - 'Onix'.
As soluções de polietileno glicol-6000 (PEG-6000) foram preparadas obedecendo-se ao esquema seguinte, com base em Villela et al. (1991):

\begin{tabular}{ccc}
\hline $\begin{array}{c}\text { Solução } \\
(\mathrm{N})\end{array}$ & $\begin{array}{c}\text { Concentração } \\
\left(\mathrm{g} \mathrm{PEG} \mathrm{kg}^{-1} \text { de água }\right)\end{array}$ & $\begin{array}{c}\text { Tensão Osmótica } \\
(\mathrm{MPa})\end{array}$ \\
\hline $\mathrm{N}_{1}$ & 0,0 & 0,0 \\
$\mathrm{~N}_{2}$ & 119,571 & $-0,2$ \\
$\mathrm{~N}_{3}$ & 178,343 & $-0,4$ \\
$\mathrm{~N}_{4}$ & 223,664 & $-0,6$ \\
$\mathrm{~N}_{5}$ & 261,948 & $-0,8$ \\
$\mathrm{~N}_{6}$ & 295,713 & $-1,0$ \\
\hline
\end{tabular}

Combinando-se as dez cultivares (C) com os seis níveis de tensão osmótica $(\mathrm{N})$ formaram-se 60 tratamentos. O delineamento experimental adotado foi o inteiramente casualizado, em esquema fatorial 10 × 6, com 4 repetições.

Foi utilizado um germinador marca National, modelo 3512-11, de prateleiras horizontais e controle automático de temperatura, com sensibilidade de $\pm 0,5^{\circ} \mathrm{C}$, enquanto previamente e durante o período de cinco dias anteriores ao início do experimento, aferiu-se a temperatura, mantendo-a estável em $25^{\circ} \mathrm{C}$. A umidade relativa no interior do germinador foi mantida próximo à saturação, com sistema próprio de circulação de água e ar.

De acordo com as regras para análise de sementes (Brasil, 1992) foram utilizadas, como substrato, três folhas de papel Germitest, convenientemente umedecidas com as respectivas soluções. O papel utilizado foi da marca Gel 065 , com dimensões de 389 × $250 \mathrm{~mm}$ e pH neutro; sobre duas folhas de papel Germitest, superpostas e umedecidas, foram distribuídas 50 sementes por repetição, em 7 fileiras eqüidistantes, com 7 sementes cada uma, uma delas colocada no centro; uma terceira folha do referido papel, bem umedecida com a respectiva solução, foi utilizada como cobertura protetora; em seguida, o conjunto foi dobrado em forma de cartucho e amarrado com um cordão a um terço da borda superior, anotando-se, na parte de cima, o número correspondente ao tratamento e à repetição. Acomodados os cartuchos em recipientes plásticos na posição de $45^{\circ}$, em relação à vertical, o conjunto foi colocado no germinador, regulado para a temperatura preestabelecida $\left(25^{\circ} \mathrm{C}\right)$. No decorrer do experimento o conjunto foi umedecido com a mesma solução de PEG-6000, de modo a se manter os níveis desejados de tensões.

A avaliação do teste de germinação foi efetivada segundo as regras para análise de sementes (Brasil, 1992), em duas contagens, nos $5^{\circ}$ e $9^{\circ}$ dias após a semeadura, considerando-se germinadas as sementes que apresentavam comprimento mínimo da radícula igual a $1,5 \mathrm{~cm}$, com base em procedimentos metodológicos relatados na literatura (Magalhães \& Carelli 1972) sobre germinação de Phaseolus vulgaris. As plântulas anormais e as sementes infectadas foram interpretadas segundo as regras para análise de sementes (Brasil, 1992); outrossim, os dados de percentagem de germinação $(\mathrm{P})$ foram transformados em $\operatorname{arcsen}(\mathrm{P} / 100)^{1 / 2}($ Souza, 1978) para adequação dos dados a uma distribuição normal. Como o fator 'Níveis de tensão osmótica' (N) é quantitativo, os valores relativos a $\mathrm{N}$ foram submetidos a estudos de regressão polinomial, seguindo-se recomendações contidas em Santos et al (1998); os dados referentes ao fator 'Cultivar', de caráter qualitativo, foram analisados pelo teste de Tukey, obedecendo-se as orientações contidas em Pimentel Gomes (1985) para esquema fatorial. 


\section{RESULTADOS E DISCUSSÃO}

Na Tabela 1 estão os resultados principais da análise de variância, realizada com os dados de sementes infectadas e plântulas anormais, obtidos nos estudos de germinação, em função dos tratamentos e dos genótipos de feijoeiro. Observam-se efeitos altamente significativos $(\mathrm{p}<0,01)$ para cultivares $(\mathrm{C})$, níveis de tensão osmótica $(\mathrm{N})$ e para a interação $\mathrm{C}$ x N. Pelo efeito interativo, a ocorrência de sementes infectadas e de plântulas anormais variou em função dos níveis de pressão osmótica, obtidos com polietileno glicol.
Por ser o fator N quantitativo, fez-se o desdobramento da interação, através de regressão polinomial, estudando-se a variação ocorrida em cada cultivar (C), decorrente dos níveis de PEG-6000 (fator N dentro de cada genótipo) cujos dados estão, também, na Tabela 1.

Observa-se que o efeito da pressão osmótica variou de uma cultivar para a outra. A utilização de PEG-6000, baixando o potencial osmótico do meio, resultou na infecção de sementes de todos os genótipos, acontecendo o mesmo em relação ao percentual de plântulas anormais, com exceção da cv. 'A-285', em que não houve efeito significativo do estudo de regressão.

Tabela 1. Resumo de análise de variância e de regressão polinomial, para sementes infectadas e plântulas anormais, obtidos na germinação das cultivares de feijão, em função dos níveis de pressão osmótica

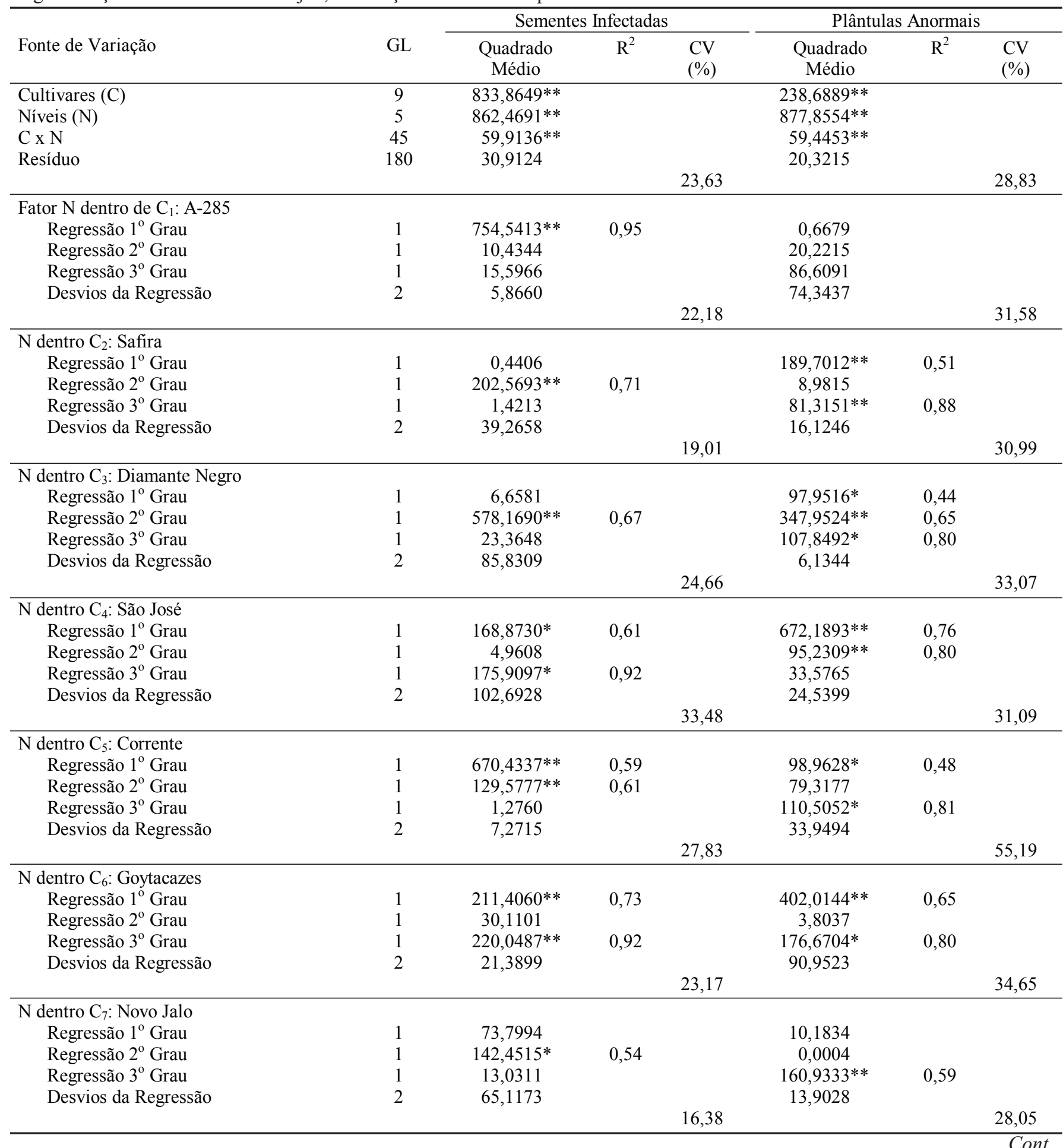




\begin{tabular}{|c|c|c|c|c|c|c|c|}
\hline \multirow[b]{2}{*}{ Fonte de Variação } & \multirow[b]{2}{*}{ GL } & \multicolumn{3}{|c|}{ Sementes Infectadas } & \multicolumn{3}{|c|}{ Plântulas Anormais } \\
\hline & & $\begin{array}{l}\text { Quadrado } \\
\text { Médio }\end{array}$ & $\mathrm{R}^{2}$ & $\begin{array}{l}\mathrm{CV} \\
(\%)\end{array}$ & $\begin{array}{l}\text { Quadrado } \\
\text { Médio }\end{array}$ & $\mathrm{R}^{2}$ & $\begin{array}{l}\mathrm{CV} \\
(\%)\end{array}$ \\
\hline $\begin{array}{c}\mathrm{N} \text { dentro } \mathrm{C}_{8} \text { : Jalo Precoce } \\
\text { Regressão } 1^{\circ} \mathrm{Grau} \\
\text { Regressão } 2^{\circ} \mathrm{Grau} \\
\text { Regressão } 3^{\circ} \mathrm{Grau} \\
\text { Desvios da Regressão }\end{array}$ & $\begin{array}{l}1 \\
1 \\
1 \\
2\end{array}$ & $\begin{array}{c}234,8945^{* *} \\
270,0978^{* *} \\
279,2865^{*} \\
9,8976\end{array}$ & $\begin{array}{l}0,69 \\
0,80 \\
0,96\end{array}$ & 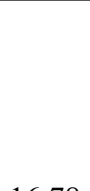 & $\begin{array}{c}128,0633^{*} \\
23,2388 \\
344,0716^{* *} \\
30,8710\end{array}$ & $\begin{array}{l}0,46 \\
0,96\end{array}$ & \\
\hline & & & & 16,78 & & & 32,18 \\
\hline $\begin{array}{c}\text { N dentro } \mathrm{C}_{9} \text { : Xamego } \\
\text { Regressão } 1^{\circ} \mathrm{Grau} \\
\text { Regressão } 2^{\circ} \mathrm{Grau} \\
\text { Regressão } 3^{\circ} \mathrm{Grau} \\
\text { Desvios da Regressão }\end{array}$ & $\begin{array}{l}1 \\
1 \\
1 \\
2\end{array}$ & $\begin{array}{c}246,1451 * * \\
154,2778^{* *} \\
52,3249 \\
4,5603\end{array}$ & $\begin{array}{l}0,63 \\
0,79\end{array}$ & & $\begin{array}{c}663,5315^{* *} \\
231,8357^{* *} \\
140,6093^{* *} \\
37,9054\end{array}$ & $\begin{array}{l}0,59 \\
0,81 \\
0,94\end{array}$ & \\
\hline & & & & 23,91 & & & 28,48 \\
\hline $\begin{array}{l}\text { N dentro } \mathrm{C}_{10} \text { : Ônix } \\
\text { Regressão } 1^{\circ} \mathrm{Grau} \\
\text { Regressão } 2^{\circ} \mathrm{Grau} \\
\text { Regressão } 3^{\circ} \mathrm{Grau} \\
\text { Desvios da Regressão }\end{array}$ & $\begin{array}{l}1 \\
1 \\
1 \\
2\end{array}$ & $\begin{array}{c}313,5965^{* *} \\
510,6785^{* *} \\
0,7290 \\
8,3576\end{array}$ & $\begin{array}{l}0,52 \\
0,82\end{array}$ & & $\begin{array}{c}682,7836^{* *} \\
16,4035 \\
78,1531 \\
57,2747\end{array}$ & 0,80 & \\
\hline & & & & 25,18 & & & 37,36 \\
\hline
\end{tabular}

\section{Infecção de sementes}

Os efeitos dos tratamentos podem ser mais bem visualizados através das Figuras 1 e 2, em que estão contidos os modelos matemáticos para cada cultivar, em função dos níveis de tensão osmótica. A infecção pode ter origem nas próprias sementes que vieram já infectadas, ou ser decorrente da manipulação durante os testes de germinação e como última hipótese, a causa de infecção pode ter sido o polietileno glicol. Ressaltase que os rolos de papel Germitest, em que as sementes foram postas para germinar, só foram abertos uma vez, por ocasião da avaliação, procedimento análogo para todos os materiais genéticos.

Dentre as possíveis causas acredita-se que a fonte primária de infecção seja a fase de produção de sementes, fato também verificado por Pereira et al. (1998) trabalhando com cultivares de algodão, disseminando-se o patógeno no meio, com polietileno glicol. Pelo que se pode constatar no presente trabalho, ocorreu grande variação entre os genótipos; nas cultivares 'Novo Jalo' e 'Jalo Precoce', o percentual de infecção estava em torno de $20 \%$, já no tratamento testemunha, em que não foi utilizado o PEG-6000; foram também altos os percentuais de sementes infectadas em 'Diamante Negro' e 'A-285'. Nas cultivares 'Jalo Precoce' e 'Diamante Negro', a infecção atingiu mais de $30 \%$ das sementes, no nível mais alto de pressão osmótica, enquanto em 'Novo Jalo', isto aconteceu já no tratamento de - 0,6 MPa. Pelos dados do desdobramento do fator Cultivar dentro de cada nível de N, contidos na Tabela 2, constata-se que nos níveis mais altos de pressão osmótica as cultivares 'Novo Jalo' e 'Diamante Negro' apresentaram os maiores percentuais de sementes infectadas. Pereira et al. (1998) observaram também, incremento da percentagem de sementes infectadas em algodoeiro, com o aumento da concentração de PEG-6000.

Verifica-se que a cultivar 'Corrente' foi a menos afetada pela infecção, até o nível de -0,4 MPa de tensão osmótica (Figura 1 e Tabela 2). Na 'Xamego', com cerca de $12 \%$ de sementes

Tabela 2. Valores de Quadrados Médios e comparação de médias pelo teste Tukey, para plântulas anormais e sementes infectadas, obtidos pelo desdobramento da interação C x N (Cultivares dentro de cada nível de pressão osmótica)

\begin{tabular}{|c|c|c|c|c|c|c|c|c|c|c|c|c|}
\hline \multirow[b]{2}{*}{ Nível } & \multirow[b]{2}{*}{ G.L. } & \multirow[b]{2}{*}{$\begin{array}{l}\text { Quadrados } \\
\text { Médios }\end{array}$} & \multicolumn{10}{|c|}{ Médias (\%) para cada Cultivar e Comparação pelo Teste Tukey } \\
\hline & & & $\begin{array}{c}\mathrm{C}_{1}: \\
\mathrm{A}-285\end{array}$ & $\begin{array}{c}\mathrm{C}_{2}: \\
\text { Safira }\end{array}$ & $\begin{array}{c}\mathrm{C}_{3}: \\
\text { Diam. } \\
\text { Negro }\end{array}$ & $\begin{array}{l}\mathrm{C}_{4}: \\
\text { São } \\
\text { José }\end{array}$ & $\begin{array}{c}\mathrm{C}_{5}: \\
\text { Corrente }\end{array}$ & $\begin{array}{c}\mathrm{C}_{6}: \\
\text { Goytacazes }\end{array}$ & $\begin{array}{c}\mathrm{C}_{7}: \\
\text { Novo } \\
\text { Jalo }\end{array}$ & $\begin{array}{c}\mathrm{C}_{8}: \\
\text { Jalo } \\
\text { Precoce }\end{array}$ & $\begin{array}{c}\mathrm{C}_{9}: \\
\text { Xamego }\end{array}$ & $\begin{array}{l}\mathrm{C}_{10}: \\
\text { Onix }\end{array}$ \\
\hline $\mathrm{N}_{1}$ & 9 & $136,3288 * *$ & $9,98 \mathrm{abc}$ & $11,54 \mathrm{ab}$ & $15,34 \mathrm{ab}$ & $7,04 \mathrm{bc}$ & $4,05 \mathrm{c}$ & $11,54 \mathrm{abc}$ & $22,38 \mathrm{a}$ & $19,37 \mathrm{a}$ & $12,25 \mathrm{abc}$ & $11,54 \mathrm{abc}$ \\
\hline $\mathrm{N}_{2}$ & 9 & $140,2247 * *$ & $12,92 \mathrm{abc}$ & $14,18 \mathrm{ab}$ & $19,37 \mathrm{ab}$ & $11,54 \mathrm{bc}$ & $4,05 \mathrm{c}$ & $11,54 \mathrm{abc}$ & $22,38 \mathrm{a}$ & $19,37 \mathrm{ab}$ & $14,18 \mathrm{abc}$ & $11,54 \mathrm{abc}$ \\
\hline $\mathrm{N}_{3}$ & 9 & $300,7503 * *$ & $16,96 \mathrm{~b}$ & $14,18 \mathrm{bc}$ & $20,27 \mathrm{~b}$ & $11,54 \mathrm{bc}$ & $4,05 \mathrm{c}$ & $14,18 b$ & $26,56 \mathrm{a}$ & $21,97 \mathrm{~b}$ & $14,18 \mathrm{bc}$ & $12,25 \mathrm{bc}$ \\
\hline $\mathrm{N}_{6}$ & 9 & $215,6013 * *$ & $27,97 \mathrm{ab}$ & $20,27 \mathrm{bcd}$ & $32,27 \mathrm{a}$ & $16,43 \mathrm{ab}$ & $15,34 \mathrm{~cd}$ & 25,10 abcd & $31,63 \mathrm{a}$ & $32,27 \mathrm{a}$ & $24,73 \mathrm{abc}$ & $26,92 \mathrm{abc}$ \\
\hline \multicolumn{13}{|c|}{ Plântulas anormais $\quad($ d.m.s. $=10,21)$} \\
\hline $\mathrm{N}_{1}$ & 9 & $118,2365 * *$ & $4,05 \mathrm{ab}$ & $1,40 \mathrm{c}$ & $1,40 \mathrm{bc}$ & $1,40 \mathrm{c}$ & $1,40 \mathrm{bc}$ & $1,40 \mathrm{abc}$ & $4,05 \mathrm{a}$ & $5,74 \mathrm{ab}$ & $5,74 \mathrm{bc}$ & $1,40 \mathrm{bc}$ \\
\hline $\mathrm{N}_{2}$ & 9 & 11,7509 & $12,92 \mathrm{a}$ & $1,40 \mathrm{a}$ & $4,05 \mathrm{a}$ & $1,40 \mathrm{a}$ & $4,05 \mathrm{a}$ & $11,54 \mathrm{a}$ & $15,34 \mathrm{a}$ & $12,25 \mathrm{a}$ & $7,04 \mathrm{a}$ & $5,74 \mathrm{a}$ \\
\hline $\mathrm{N}_{3}$ & 9 & $74,4147 * *$ & $12,25 \mathrm{ab}$ & $9,98 \mathrm{ab}$ & $14,18 \mathrm{ab}$ & $7,04 \mathrm{~b}$ & $9,10 \mathrm{ab}$ & $13,56 \mathrm{ab}$ & $16,43 \mathrm{a}$ & $11,54 \mathrm{ab}$ & $16,43 \mathrm{a}$ & $5,74 \mathrm{~b}$ \\
\hline
\end{tabular}



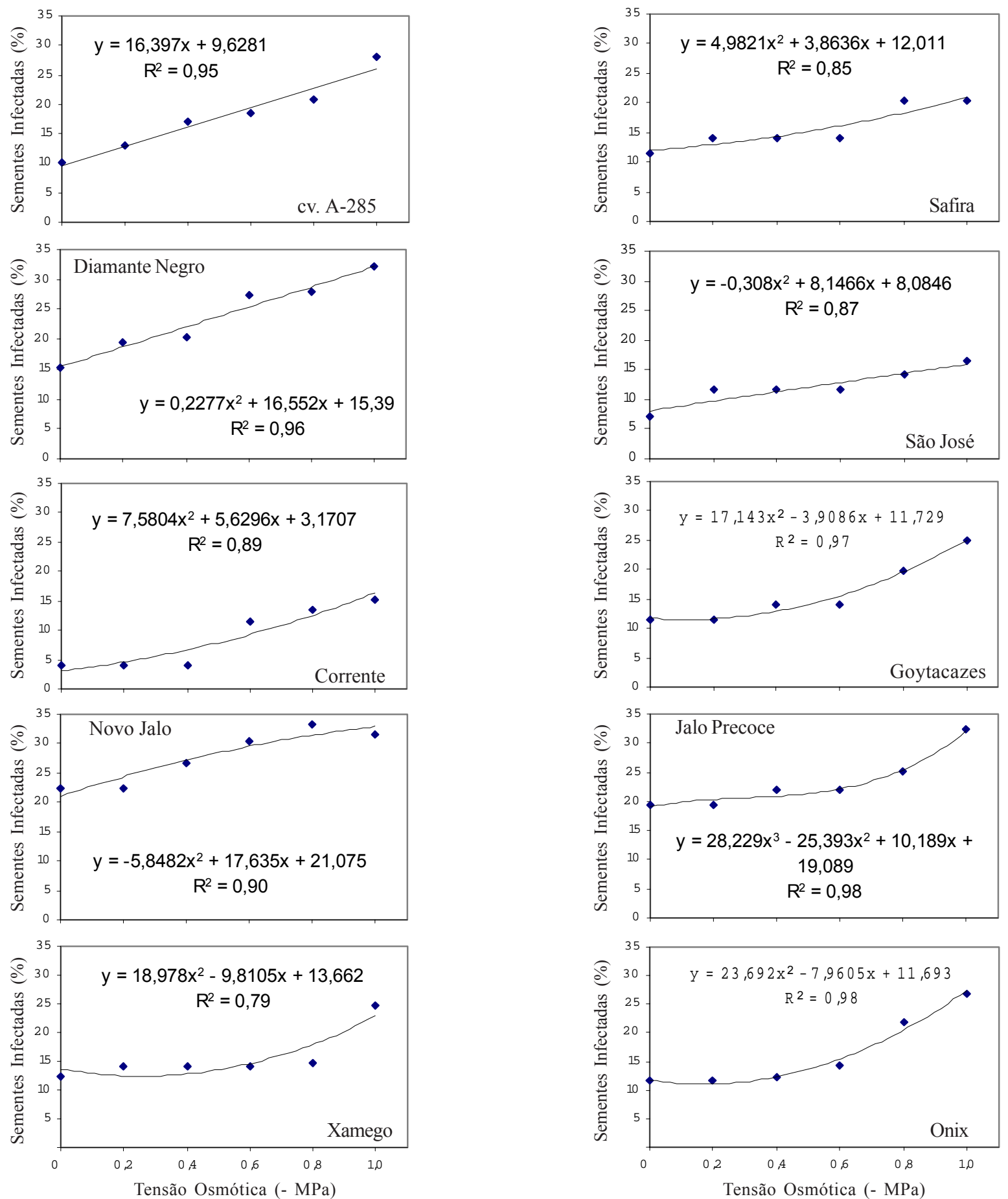

Figura 1. Percentagens de sementes infectadas observadas na germinação de sementes de cada cultivar de feijão, em função dos níveis de tensão osmótica, com os respectivos modelos matemáticos de regressão polinomial

infectadas no tratamento-testemunha, com o aumento da concentração de PEG-6000 este percentual subiu um pouco, mantendo-se, porém, inferior a $15 \%$, mesmo na tensão de - $0,8 \mathrm{MPa}$. As cultivares 'Corrente' e 'São José' mantiveram idêntico grau de infecção, inferior a 15\% no tratamento - 0,8 MPa.

\section{Anormalidade de plântulas}

Quanto à incidência de anormalidades de plântulas verifica-se que foi sempre crescente, com o aumento da pressão osmótica nas cultivares 'Goytacazes' e 'Onix'. Na maior parte dos genótipos ('Diamante Negro', 'Corrente', 'Novo Jalo', 'Jalo Precoce', 'São José' e 'Xamego'), a anormalidade aumentou com a concentração de PEG-6000 até a faixa entre - 0,6 e - 0,8 MPa, enquanto na cultivar 'Safira' o aumento do percentual de anormalidades aconteceu até a última faixa de $-0,8$ a -1,0 MPa; na cv. 'Xamego' chegou a atingir mais de $20 \%$ das sementes, entre - 0,6 e - 0,8 MPa. Nicnow et al. (1991) e Pereira et al. (1998) também encontraram elevação do percentual de plântulas anormais quando em contato com soluções osmóticas de PEG, em níveis crescentes.

As principais anormalidades observadas no trabalho consistiram em ausência ou atrofiamento de radícula, ausência de raiz principal ou de raízes secundárias. El-Scharkawi \& Springuel (1977) trabalhando com níveis crescentes de 

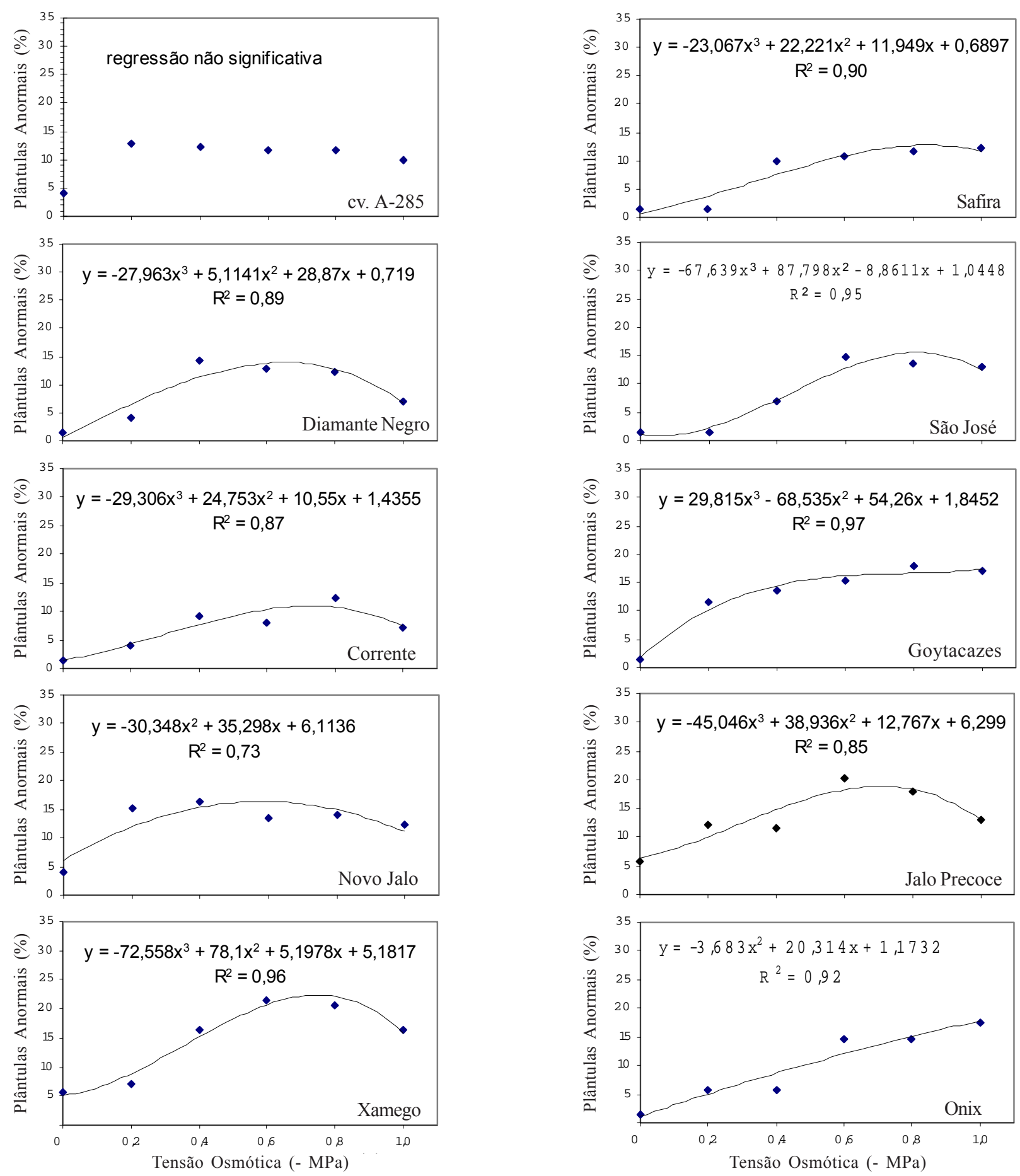

Figura 2. Plântulas anormais (\%) observadas em cada cultivar de feijão, em função dos níveis de tensão osmótica, com os respectivos modelos matemáticos de regressão

PEG-6000 na germinação de trigo, cevada e sorgo, relatam que os principais efeitos de anormalidades ocorrem sobre a emergência da radícula.

Segundo Emmerich \& Hardegree (1990) é possível que a anormalidade das plântulas seja influenciada pela alta viscosidade do PEG e sua baixa solubilidade em oxigênio, agravando-se com o aumento da concentração do produto; entretanto, pelos dados obtidos no presente trabalho e por aqueles relatados por Pereira et al. (1998) pode-se afirmar que o oxigênio não deve ter-se tornado limitante, já que ocorreu multiplicação, até excessiva, de patógenos (infecção) nas sementes, mesmo nos tratamentos de maior concentração de polietileno-glicol.
Pelos modelos matemáticos, Figura 2, nota-se que a cv. 'Corrente' foi a menos afetada por anormalidades na germinação, seguida pela 'Diamante Negro'. É o que pode ser visto também pelos dados da Tabela 2, em que no nível $\mathrm{N}_{6}(-1,0 \mathrm{MPa})$, essas duas cultivares foram as que tiveram menor média de anormalidades. Segundo Nicnow et al. (1991) podem ser encontrados materiais genéticos mais resistentes a anormalidades causadas pelo uso de PEG-6000, durante a germinação de sementes. Foi o que verificaram Pereira et al. (1998) trabalhando com diversos genótipos de algodoeiro herbáceo, identificando os mais tolerantes e os mais susceptíveis. 


\section{CONCLUSÕES}

1. A percentagem de sementes infectadas aumenta à medida que se elevam os níveis de concentração do PEG-6000.

2. Na maior parte dos genótipos aumenta a anormalidade com a concentração de PEG-6000 até a faixa de pressão osmótica entre - 0,6 e - 0,8 MPa, com exceção das cultivares 'Goytacazes" e 'Onix' em que foi sempre crescente com a concentração de PEG-6000.

3. Na cultivar 'Corrente' foram observados os menores índices de anormalidade e de infecção, podendo ser classificada como a mais tolerante.

4. Podem ser consideradas tolerantes à infecção as cultivares 'São José' até - 0,6 MPa e 'Xamego' até - 0,8 MPa de pressão osmótica.

5. As cultivares 'Novo Jalo', 'Jalo Precoce' e 'Goytacazes' foram as mais afetadas por infecção de sementes e anormalidade de plântulas.

6. As principais anormalidades observadas no trabalho consistiram em ausência ou atrofiamento de radícula, ausência de raiz principal ou de raízes secundárias

\section{REFERÊNCIAS BIBLIOGRÁFICAS}

BRADFORD, K.J. Manipulation of seed water relations via osmotic priming to improve germination under stress. Hortscience, Alexandria, v.21, n.5, p.1105-1112, 1986.

BRASIL, Ministério da Agricultura. Regras para análise de sementes. Brasília: Departamento Nacional de Produção Vegetal, 1992.188p.

EL-SCHARKAWI, H.N.; SPRINGUEL, I. Germination of some crop plant seeds under reduced water potential. Seed Science \& Technology, Zurich, v.5, p.677-688, 1977.

EMMERICH, W.E. \& HARDEGREE, S.P. Polyethylene glycol solution contact effects on seed germination. Agronomy Journal, Madison, v.82, p.1103-1107, 1990.

FAGERIA, N.K. Eficiência de uso de fósforo pelos genótipos de feijão. Revista Brasileira de Engenharia Agrícola e Ambiental, Campina Grande, v.2, n.2, p.128-131, 1998.
FIEGENBAUM, V.; SANTOS, D.S.B. dos; MELLO, V.D.C.; SANTOS FILHO, B.G. dos; TILLMAN, M.A.A.; SILVA, J.B. da. Influência do déficit hídrico sobre os componentes de rendimento de três cultivares de feijão. Pesquisa Agropecuária Brasileira., Brasília, v.26, n.2, p.275-280, 1991.

MAGALHÃES, A.C.; CARELLI, M.L. Germinação de sementes de feijão (Phaseolus vulgaris L.) sob condições variadas de pressão osmótica. Bragantia, Campinas, v.31, n.32, p.19-26, 1972.

NICNOW, A.W.; BUJALSKI, W., PETCH, G.M.; GRAY, D.; DREW, R.L.K. Bulk priming and drying of leek seeds: The effects of two polymers of polyethylene glycol and fluidized bed drying. Seed Science \& Technology, Zurich, v.19, p.107-116, 1991.

PEREIRA, J.R.; FERNANDES, P.D.; BELTRÃO, N.E. de M. Deterioração, endurecimento e anormalidades em sementes e plântulas de algodoeiro herbáceo (Gossypium hirsutum L.r. latifolium H.) sob estresse hídrico. Revista Brasileira de Engenharia Agrícola e Ambiental, Campina Grande, v.2, p.186-194, 1998

PIMENTEL GOMES, F. Curso de estatística experimental. Piracicaba: Universidade de São Paulo, ESALQ., Nobel, 466p, 1985.

ROSELEM, C.A. Nutrição e adubação do feijoeiro. Piracicaba: Associação Brasileira para Pesquisa da Potassa e do Fosfato, 1987.93p. Boletim Técnico, 8

SANTOS, J.W. dos; MOREIRA, J. de A.N.; BELTRÃO, N.E. de M. Avaliação do emprego dos testes de comparação de médias na Revista Agropecuária Brasileira de 1980 a 1994. Pesquisa Agropecuária Brasileira, Brasília, v.31, n.3, p.225-230, 1998.

SHARMA, M.L. Interaction of water potential and temperature effects on germination of three semi-arid plant species. Agronomy Journal, Madison, v. 68, n.2, p.390-394, 1976.

SOUZA, B.B. de. Uso de transformações que visam à homocedasticidade. Brasília: Universidade de Brasília Departamento de Estatística, jan. 1978.

VILLELA, F.A.; DONI FILHO, L.; SIQUEIRA, E.L. Tabela de potencial osmótico em função da concentração de polietileno glicol 6000 e da temperatura. Pesquisa Agropecuária Brasileira, Brasília, v.26, n.11/12, p.1957-1968, 1991. 